\title{
Hosting a Pipeline of K-12 Robotics Competitions at a College of Engineering - A Review of Benefits and Challenges
}

\author{
Tanja Karp, $\mathrm{PhD}$ \\ Electrical and Computer Engineering Department \\ Texas Tech University \\ Lubbock, TX 79409, USA \\ tanja.karp@ttu.edu \\ Mangnan (George) Tan \\ Undergraduate Student \\ Electrical and Computer Engineering Department \\ Texas Tech University \\ Lubbock, TX 79409, USA \\ george.tan@ttu.edu
}

\author{
Richard Gale, $\mathrm{PhD}$ \\ Electrical and Computer Engineering Department \\ Texas Tech University \\ Lubbock, TX 79409, USA \\ richard.gale@ttu.edu \\ Greg Burnham \\ Allen High School, Allen ISD \\ 300 Rivercrest Blvd \\ Allen, TX 75002 \\ greg_burnham@allenisd.org
}

\begin{abstract}
This paper describes a pipeline of $\mathrm{K}-12$ robotics challenges, which not only excites and engages elementary through high school students but also provides valuable educational experiences to engineering undergraduate and graduate students from Texas Tech University through formal class work, volunteer opportunities, and engagement in student organizations. It describes the benefits of the robotics programs seen by the participants, school teachers, undergraduate and graduate students, and university faculty as well as struggles and pitfalls experienced.
\end{abstract}

Index Terms - community engagement, K-12 robotics competitions, service learning, student organizations

\section{INTRODUCTION}

Robotics programs have proven to be a successful tool to engage K-12 students in science, technology, engineering, and math (STEM) and create interest in careers in the STEM fields ${ }^{12} 3$. Robotics has also been recognized as a topic that easily excites college-level engineering students, offering hands-on experience to support theoretical concepts, and fostering multidisciplinary work. ${ }^{24}$

The Whitacre College of Engineering (WCOE) at Texas Tech University (TTU) ${ }^{5}$ has a long tradition of engaging in engineering outreach through the Texas Tech T-STEM Center ${ }^{6}$ and through departmental initiatives. Over the last two decades a pipeline of robotics challenges for students in grades K-12 has been implemented to expose participants to engineering as early as in elementary school and to keep them involved and interested until they enter college. At each level of the pipeline, K-12 participants and teachers interact with engineering students who serve as mentors, organizers, and volunteers, but most importantly provide role models for the 
participants. This is particularly important in rural communities where $\mathrm{K}-12$ students have limited access to engineering professionals. At the university, the robotics programs have created a community of scholars, strengthening relationships between faculty and staff from different disciplines and colleges, all of whom are interested in promoting careers in STEM through summer camps ${ }^{7}$ or teaching pedagogy such as service learning ${ }^{8}$.

The robotics challenges annually offered by WCOE at TTU consist of:

- Get Excited About Robotics (GEAR) ${ }^{9}{ }^{10}$, a 6-8 week LEGO robotics competition for elementary and middle school students

- Boosting Engineering Science and Technology (BEST) robotics ${ }^{11}$, a six week robotics program for middle and high school students where students build a robot from a set of consumables and a VEX controller

- FIRST Tech Challenge ${ }^{12} 13$, a LEGO MINDSTORMS based challenge for high school students

- FIRST Robotics Competition ${ }^{14} 15$

Each program is run by a tenured faculty of WCOE who is supported by 1-2 paid graduate students and several undergraduates. Faculty coordinate competition dates to avoid conflicts, share equipment needed to host the competitions, and collaborate on securing funding and disseminating results. The college and university support these programs financially through graduate student support and by covering some of the event and travel expenses. They also promote the programs through media communications and development offices.

While BEST robotics has been in place at TTU since 1995, the implementation of the other programs over the last 10 years was initiated by committed faculty (GEAR) or enthusiastic students (FIRST) and facilitated by Texas Workforce Development grants recognizing the need to increase expertise in STEM disciplines and increase enrollment in engineering undergraduate programs. Goals of the programs are to expose students to careers in STEM through exciting hands-on challenges and to promote a college-going mindset.

This paper describes important elements of a K-12 robotics pipeline along with our efforts to collect data and analyze results. We discuss several ways in which undergraduate and graduate students in the college of engineering are involved in this pipeline, and the effects of this involvement on their engagement, self-efficacy, and academic achievement. We then look at the effects these programs have on community partners in participating schools, students and teacher/coaches. Before we present our conclusions, we will discuss how the robotics programs benefit the sponsoring faculty and the struggles in keeping all the robotics programs active.

\section{Description of Two K-12 Robotics Programs OfFered}

This section describes the two K-12 robotics programs in the pipeline that have seen the largest growth in participation and impact at the university and community level over the last decade: GEAR and FIRST Robotics. 


\section{Get Excited About Robotics (GEAR) for Grades K-8}

GEAR $^{10}$ is a 6-8 week robotics challenge using the LEGO MINDSTORMS NXT and EV3 kits. It is offered at several locations in Texas on an annual basis. There is no cost to participants other than time and travel and the competition is open to all interested elementary and middle schools and afterschool clubs. During the GEAR challenge, participants design, program, troubleshoot, test, and improve their robots in teams of 2-5 students at their schools/clubs under the guidance of a teacher/coach. The theme of the competition changes every year and is motivated by real world applications of robotics (automated farming, robotic surgery, unmanned space travel, etc.). At game day, teams compete on a 4' x 8' game table in two minute rounds during which they need to accomplish as many of the challenge tasks as possible. Each task is associated with a score related to its difficulty. GEAR is similar to FIRST LEGO League (FLL) ${ }^{16}$ but the challenges are easier to accomplish than in FLL. GEAR is, thus, an excellent introduction to robotics in which students can gain their first experiences in an environment that is neither intimidating nor overwhelming. In addition, participation in GEAR is less expensive than FLL and offers more flexibility to the organizers with respect to time and competition logistics.

The Lubbock GEAR tournament ${ }^{11}$ has been hosted at TTU since 2006 and has seen continued growth in participation from a single elementary school with 20 students in its first year to about 700 participants in 2014 coming from over 50 different elementary and middle schools and 4-H clubs from the entire northwest quadrant of Texas. Selection of GEAR participants is performed by teachers/coaches who also provide meeting facilities for their teams. Participants visit the university campus for three events. During kick-off they learn about the current challenge and real world engineering applications related to it. They then obtain their game pieces and mat and can check out up to six LEGO MINDSTORMS kits per school/club at no cost for the duration of the competition. After four weeks teams return to campus for a trial run under competition-like constraints at the same location as the competition will be held. This event provides participants with the opportunity to learn from other teams and evaluate their performance. Finally, teams return to campus at the end of the challenge for game day when they compete for awards. Engineering freshmen mentor local GEAR teams in collaboration with K-12 teachers/coaches. Engineering students also participate in the organization of the three oncampus events. During trial run and game day, the engineering students are responsible for setup, judging, scoring, and cleanup. The participation of engineering students has turned out to be a huge selling point when recruiting new teachers into the program.

For many years, a new teacher training workshop was offered on a Saturday morning about a month before the GEAR kick-off event. It provided teachers with information on the GEAR program as well as a hands-on introduction to LEGO robotics. In 2013, this workshop was replaced by an online robotics course ${ }^{17}$ that provides videos and worksheets for teachers/coaches.

\section{FIRST Robotics for Grades 9-12}

FIRST Robotics (FRC) is the flagship robotics competition ${ }^{15}$. The WCOE has hosted and sponsored FIRST Robotics Team 1817, the Llano Estacado RoboRaiders ${ }^{16}$ since 2007 . The uniqueness of this team is that it consists of participants from a variety of area middle and high schools and homeschoolers and is mentored by TTU engineering students. The team was 
founded by two undergraduate students who had participated on FIRST teams in high school, and it is now an official student organization at TTU.

High school and college students cooperate in small teams organized around the competition tasks: robot design, manufacturing, assembly and test, parts and material logistics, marketing, finance, and event planning. Additional teams are composed of drivers, on-venue repair and maintenance personnel, and contestants for the essay/presentation-based awards.

The competition kicks off the first Saturday in the calendar year and robots must be sealed and/or shipped to the regional competition site for which the team registered after six weeks. The design challenge changes each year but always involves a moving base and a manipulator for some sort of game piece. Game pieces come in a variety of shapes and sizes and often mimic sports events - soccer, basketball, etc.. Usually there are obstacles or bonus points that further complicate the design of the moving base. The competition involves both an autonomous period and a tele-operated period. Each team can only build one competition robot and the robot cannot use any custom designs or components from previous years; however, those components can be modified and then be reused. This rule encourages teams to analyze and improve their previous designs. Each robot weighs approximately $150 \mathrm{lbs}$, must fit into game specific dimension at the beginning of the competition, and must pass safety inspection. The competition takes place on a $27^{\prime} \times 54^{\prime}$ field and is played by 6 robots at a time, two alliances of three robots each, which forces teams to collaborate with each other to optimize their performance.

For seven years Team 1817 was the only FRC team within 300 miles. Part of the FIRST value proposition is increasing participation and inspiring new teams. So Team 1817 developed a program of education and outreach that partnered with the university and college to increase awareness of STEM careers. Team 1817 received the Chairman's Award, the highest recognition in the FIRST competition, at the Dallas regional competition in 2012, in large part due to these efforts. In 2013 the Texas Workforce Commission, working through FIRST in Texas, provided funding for a number of new teams in Texas. Team 1817 took a leadership role working with FIRST in Texas ${ }^{18}$ to identify high schools throughout the surrounding area and to work with them to create a total of 9 new teams. Additionally, Team 1817 worked with the national FIRST organization to create the FIRST Robotics Hub City Regional Competition in Lubbock. The inaugural year saw participation by 38 teams. Team 1817's achievements in realizing the FIRST mission to expand participation was recognized by the Judges' Award in 2013. In 2014 there were 41 teams including 10 local teams. The majority of the event organizers and volunteers were Team 1817 mentors and alumni.

\section{Evaluation Methods}

The results represented in the following sections describing the impacts of the K-12 robotics pipelines on engineering students, K-12 participants, teachers, and faculty were gathered over the last years using mixed methods. The GEAR program annually collects data from teachers/coaches regarding team demographics, motivation of participating in the program, and benefits of the program. GEAR participants competing for the Young Engineers Award submit a two page essay describing their teamwork and design experience. Engineering students mentoring GEAR participants as part of a service learning projects write reflection papers for course credit. FIRST robotics participants and mentors informally share their experiences with faculty and teachers involved in the program. Finally, the authors have been involved in the 
described programs as organizers, faculty advisor, teacher, and mentor for nearly a decade and contribute their personal experiences.

\section{IMPACTS OF K-12 ROBOTICS CHALLENGES ON ENGINEERING UNDERGRADUATE STUDENTS}

In addition to providing exciting hands-on challenges that promote STEM and engineering in particular to students in grades K-12, another motivation of organizing the robotics pipeline as a college of engineering is to provide educational opportunities to engineering students currently enrolled at TTU. This section describes the major ways in which engineering undergraduate and graduate students are involved in the $\mathrm{K}-12$ robotics programs.

\section{Service Learning}

Since 2010 a Service Learning section of ENGR 1315 Introduction to Engineering has been offered every spring semester ${ }^{19}$. ENGR 1315 is a freshman level engineering course required by most engineering majors. The course is mainly taken by engineering and pre-engineering freshmen during their first year at TTU. It provides an "introduction to the engineering profession, including the distinction between different majors, engineering problem solving, [...] professionalism and ethics, and experiences in team design projects" 20 . As part of their service learning project students mentor GEAR teams in and around Lubbock. They are expected to complete 15 hours with their teams at the school/club and are required to document their mentoring experience. They also participate in GEAR events by being a leaders for their teams. Additionally, ENGR 1315 students need to write three reflection papers in which they evaluate their mentoring experience, skills required in engineering careers, and the connection between the GEAR tasks and the engineering profession. To overcome the limited experience of ENGR 1315 students in programming and designing LEGO MINDSTORMS robots, in-class activities were designed using the LEGO NXT/EV3 robotics kits. Data collection, unit conversion, statistical analysis, basic calculus concepts, and the engineering design process are taught as active-learning experiments using the LEGO kits and its software environment. A detailed description of the in-class activities and the reflection papers is given in (Karp, 2011) ${ }^{20}$. Mentoring elementary and middle school students during the 6-8 week GEAR LEGO robotics competition teaches students communication skills, critical thinking, problem solving, team work, professionalism, and leadership, i.e. skills that are hard to acquire in a classroom setting. At the same time teachers appreciate the presence of the engineering students in the classroom, often the only exposure to engineering for both, teachers and K-8th grade students alike. For the engineering students, being considered as the "engineering experts" by their school/club teams boosts their confidence to succeed in their major. A syllabus of the course is available online ${ }^{21}$. Ongoing research aims at comparing student perceptions of skills learned in the service learning section and a normal section of ENGR 1315 where students perform a team design project instead of the Service Learning project.

Through TTU's Service Learning Program ${ }^{9}$, knowledge of the robotics programs was taken outside of WCOE. One semester, students designed LEGO robotics experiments for day-long field trips for their Oral Communications class, a required class in all engineering degree plans at TTU. 


\section{Senior Design Projects, Independent Study Courses, and Master's Theses}

Projects related to robotics and the K-12 robotics programs have become popular among electrical and computer engineering seniors taking their capstone design classes. In these two classes students may choose from a variety of projects suggested and sponsored by WCOE faculty or may propose projects and recruit a faculty sponsor. Undergraduate and graduate students may also enroll in an independent study course with a faculty member to work on an engineering problem.

In the past, students have proposed the design of a daughterboard to expand the capabilities of the popular Arduino microcontroller family. This project is a result of the students' involvement in FIRST Robotics and was developed independently by the students. It has direct relevance to design and development responsibilities they will encounter in the workforce. In another project a student developed web-based curriculum for GEAR robotics and tested it with a group of elementary school students. He also was responsible for the organization of the competition that year and provided online support to teachers. Yet other projects were to characterize and understand the bandwidth limitations of the CAN (controller area network) bus $^{22}$, a standard widely used in robotics, and specifically in the FIRST robotics control system, or to take on the creation of a 3D printer to be used in manufacturing custom parts for FIRST robots. We have also approved an independent study course focusing on leadership skills development for undergraduate students organizing the FIRST Robotics team.

An electrical engineering graduate student, a veteran FIRST Robotics team member in high school and then a team leader and mentor as an undergraduate, completed his Master's thesis based on the design, construction, and programming of an autonomous quad-rotor intelligence gathering platform ${ }^{23}$. This student is now employed in industry where his skills developed in robotics are highly valued. He is also continuing his involvement in FIRST Robotics as a mentor.

\section{Student Organization Involvement}

Having been engaged in a student organization and having taken on a leadership position in it are highly sought after experiences by companies recruiting engineering students for internships or full-time employment after graduation. The K-12 robotics challenges offer ample opportunities for student organizations to get involved and increase their visibility.

The Electrical Engineering Honors Society Eta Kappa $\mathrm{Nu}(\mathrm{HKN})$ decided seven years ago to use the GEAR competition as the service project required by new initiates to show their ability to organize and lead groups of people. Since then, HKN members have played a vital role in running the competition. Most initiates and HKN officers work as table judges. Many new members of HKN repetitively participate in GEAR since they find it a very rewarding experience.

The RoboRaiders is a student organization that was founded by the engineering student mentors of FIRST Team 1817. Over the years they have broadened their focus to include STEM community outreach and the organization of the local BEST and FIRST robotics competitions. Currently, the organization consists of about 20 undergraduate and graduate students from various engineering and non-engineering majors. Its structure is very similar to a small business. The organization is broken down into technical and non-technical members. The technical members focus on design and manufacturing of the robots and the non-technical members focus on PR, marketing, and fundraising. The collaboration of technical and non-technical members gives many students a whole new perspective to the idea of teamwork. Another unique aspect of 
the organization is that its members work directly with middle and high school students and engage with their parents. The members must demonstrate a high level of technical knowledge and professionalism while also meeting legal obligations of working with minors. For overnight trips, the non-technical members get the opportunity to plan the legal and financial side of the trips. The RoboRaiders manage a $\$ 20 \mathrm{k}-60 \mathrm{k}$ annual budget, funded by the university, private grants, and local business partners. Due to this large budget, all candidates are selected through a rigorous interview process followed by a four-week training program.

The RoboRaiders also participate in the recruiting effort of the college. They showcase their robots at University Day and during campus visits of high school students. They are also present at new student orientations during the summer. Undergraduate students from all over the state who have participated in FIRST and come to TTU as freshmen immediately look up Team 1817, often during orientation. They are familiar with the team, often having worked with each other on alliances at competitions, and are enthusiastic about joining the RoboRaiders and becoming FIRST Robotics mentors. In this way a continuing supply of experienced mentors is provided who are only a year or two ahead of the high school team members. Justin Griggs, one of the undergraduate and then graduate mentors who came to TTU with a FIRST robotics high school experience and one of the founding members of the RoboRaiders has articulated the benefits of mentoring as follows: "Mentoring high school students through the demanding six week build process gave me the ability to lead and manage teams, which became useful as I progressed through my undergraduate program and worked in teams for class projects and lab classes. Being a mentor of Team 1817 in college benefitted me by providing me with a support structure throughout my undergraduate career. By interacting closely with the other college students on the team, I was given valuable advice that helped me throughout my college career. From class choices, to practical skills, to homework help; my teammates helped guide me through the curriculum."

The RoboRaiders student organization also collaborates with other engineering student organizations. The robotics programs and regional competitions provide community service opportunities. Particularly, members of student organizations of traditionally underrepresented groups in engineering (women, ethnic minorities) take up this chance to be a role model to younger students and their parents. During fall 2011, members of the Association of Women in Electrical Engineering (AWEE), and the National Society of Black Engineers (NSBE), both TTU student organizations, decided to be robotics mentors and collaborated with the RoboRaiders. They regularly visited teams at schools and helped organize the competition. Courtney Pinnell, the AWEE president at the time, stated her motivation as follows: "Throughout my academic career my engineering classes contained $10 \%$ of women at best. It was a sad reality at the start of each semester when I would walk into a classroom and realize I was the only woman in the class. As president of AWEE, I knew it was necessary for our organization to get involved in robotics programs not only to teach young kids what engineering is but to encourage minority students to get involved as well. In the fall of 2011 AWEE teamed up with NSBE, to mentor students involved in robotics. Our goal was simple: encourage diversity in engineering and teach kids the various applications of engineering."

For NSBE, the K-12 robotics challenges also offered an opportunity to its members for multi-disciplinary collaboration: getting to know students from other engineering disciplines better and building cross-departmental networks. Since the collaboration with AWEE and NSBE, the RoboRaiders has reached out to other student organizations such as IEEE, Women in 
Electrical Engineering (WIE), the Society of Hispanic Professional Engineers (SHPE), HKN, and the Engineering Ambassadors.

Even though the RoboRaiders provide opportunities for its members to learn and experience new skills, the members also face many challenges. During the year, the members spend 20-40 hours a week on planning outreach events and working with middle and high school students. The time demand increases even further during the intense six-week build season when mentors spend many all-nighters at the build site during the week. Mentors who have prior FIRST experience tend to have a better mental preparation for this than non-experienced mentors.

Faculty have noticed that mentors miss class, are tired, and do not perform up to their potential during this time frame. Due to the lack of time dedicated to coursework most mentors receive a course grade that is at least a grade level below their normal performance. Informal discussions with mentors have revealed that mentors are aware of this fact but think that it is worth it. As the former team leader Travis Ray states, "Being a FIRST mentor as well as a team leader has provided me with a lot of experience. I find myself more capable of managing large projects than my similarly aged peers." Students whose grades fall below university standards are encouraged to spend less time on robotics and are mentored in their classwork. This encouragement comes from peers, instructors, and advisors. Students have successfully recovered from their academic deficits and returned to full participation.

Mentor turnover is another challenge faced with college mentors. As mentors graduate from the university, they also take their experience with them. In order to sustain team performance and student experience, each season, the team has to train new mentors and pass down experiences from one generation to the next. A typical mentor experience is limited to no more than four years for an undergraduate student and six years for a mentor who stays on campus for graduate school. The annual training requirement adds additional time commitment to the senior mentors and further complicates time management. However, the experience in succession planning is valuable to mentors in later real-world challenges.

\section{Personal Mentor Experience}

George Tan, an electrical engineering senior at TTU, describes his personal experience with robotics as follows:

"My first involvement in robotics was in high school. I was an active member of my high school BEST robotics team. During my senior year in high school, I had an opportunity to become a part of a regional FIRST robotics team and that's where my life took a turn. I got a first look on my future career as an engineer student and my potentials.

When I first started college at Texas Tech University in 2007, I majored in biology intending on pursue a career in the medical field. As a freshman, I had an opportunity to be a robotics mentor for a few K-12 robotics programs including GEAR Robotics, BEST Robotics, and FIRST Robotics. At the time, mentoring robotics for K-12 students helped me discover my passion for engineering. My robotics mentor experience led me to change my major to electrical engineering. In the beginning, I was teaching individuals or small groups of students, which taught me the importance of teaching and to have appreciation for my teachers and what they do. Also, teaching these students robotics also helped me reinforce the concepts I had learned in my classes. Being able to apply and teach these concepts helped me become a better student in my engineer classes. Learning by teaching really gave me a new perspective on learning. Without 
International Journal for Service Learning in Engineering Special Edition, pp. 406-423, Fall 2014

ISSN 1555-9033

the mentoring experience, I would have never imagined how much I can learn from teaching a group of $K$ - 12 students.

As I became more involved in technical demanding programs such as FIRST Robotics, my technical knowledge was also expanded. Robotics engineering requires knowledge from various backgrounds of engineering, such as electrical, mechanical, industrial, and computer science. To be a good robotics mentor, just having knowledge in electrical engineering is not enough. By working with people with various backgrounds, I have learned to appreciate the dynamics of teamwork and how to be a team player, instead of an individualist. The diverse technical knowledge I have acquired as a robotics mentor helped me with my design project classes by dividing the projects based on each group member's experience and expertise to optimize the team efficiency. Also, the mechanical and programming aspect of robotics have helped me to become a better engineer.

After a few years of mentoring in different robotics programs and extended knowledge in robotics design, I had the opportunity to take a leadership role in these robotics programs. Just as I thought I knew everything about robotics, a new challenge arose: management. Being a technical mentor is very different from being a lead mentor. As a technical mentor, you get the luxury of focusing on just design or programming aspects of the robot while mentoring the students. But when you are in a leadership role, things get a whole new perspective. As the lead mentor, I had to organize local robotics events consisting of 400-500 students, teachers and parents and as a FIRST Robotics team leader I had to work with local professional engineers, teachers and student leaders of other student organizations to plan and run these events. I have learned how important communication and time management is when working with a large group of people and how to effectively using modern technology to organize, plan and communicate with other volunteers. These real life organization skills were never taught in a classroom. Also, working with local engineers gave me the opportunity to network with professionals in my field of study. Working with a real budget, real deadlines, and real limitations to build a robot is much more challenging and rewarding than a class design project. As the lead mentor, I got the opportunity to bring a group of people with different backgrounds to work together to achieve a common goal. The experience I got from being a lead mentor helped me greatly during my internship in a team and corporate environment.

Robotics is not just a mentoring or an extracurricular activity on my resume. It's a challenge, a character builder, a once in a life-time experience. Being a robotics mentor gave me the opportunity to have my first publication at an academic conference while still being an undergraduate student. It allowed me to meet many professionals in my field of studies. It gives me confidence in a job interview and allows me to give back to the community and inspire the next generation of scientists and engineers."

\section{IMPACTS OF K-12 RoBotics CHALLENGES ON K-12 TEACHERS AND STUDENTS}

Teachers and coaches spend a significant amount of time with their robotics teams before and after school and on weekends, generally without receiving additional compensation for this effort. Also, there is a low turnover rate of teachers coaching a robotics team. Unless teachers change positions within their school district they typically coach robotics for several years if not decades. Teachers who move to a new school district oftentimes convince their new principals to participate in the robotics programs they were involved in at their old school. 
The TTU GEAR program annually asks teachers to submit a team information form at game day, providing information on student demographics, selection process, motivation to participate and benefits of participation. Under "motivation to participate" teachers mention prior positive experience with the program, student interest, excitement and growth, the challenge/competition aspect, an opportunity to offer enrichment programs, and affordability. Problem solving, critical thinking, and teamwork are most often mentioned under "benefits of the program". In 2014, these were followed by benefits such as programming skills, use of creativity/outside the box thinking, building and design skills, excitement about STEM, hands-on learning, and application of math and sciences skills. A teacher from an all-female charter school describes the benefits of GEAR to his students as follows: "I noticed that some students that don't necessarily excel at competitive sports, the arts, or even academics, lack an outlet to showcase their creative capabilities or the fact that they can be motivated to compete. In robotics, I have several of these types of students that are young and haven't quite found a "niche" in any kind of afterschool activity. Robotics has given them another outlet to explore, and it's interesting to see students who don't typically succeed in STEM subject areas get completely invested in the mechanics, problem solving, and mathematics that programming and the designing of a robot require. GEAR has given those types of students an opportunity to work towards a goal and strive to be best at something - all while [...] showing relevance for a potential career in life."

Students competing for the Young Engineers Award by submitting a two page essay on their robot design describe the following topics: their group's teamwork and their work with others, their belief that their robot will be successful, how they have found additional information outside the classroom, and how much fun they had.

While GEAR has seen a significant growth in participation over the years, not every student gets the opportunity to be part of the program. The schools that offer GEAR as an afterschool enrichment program (nearly all elementary schools and more than half of the middle schools) typically use good academic standing, no behavioral issues, availability at pre-determined meeting times, and teacher recommendation for their selection of participants. Middle schools oftentimes limit participation to enrollment in elective classes such as robotics or a technology class in which the LEGO robots are also used. Only one teacher wrote: "My students had grown a lot and I wanted to give my students an opportunity to showcase their hard work. Many had mentioned they wanted to go but were never selected by the previous robotics instructor. I eliminated the selection process and allowed any students that wanted to work towards GEAR to prove they could achieve the programming tasks and design something effective to complete the challenges before them."

Several teachers involved in GEAR as coaches have taken robotics further into their schools. Robotics summer camps, new robotics elective courses, grant applications and fundraising to acquire their own LEGO robotics kits, and advertisement of the program among their teacher network are among the most commonly observed activities. Schools also showcase the robots to parents and younger students after the end of the competition, use their robotics program to recruit students into their Magnet programs, and recognize GEAR participants at end-of-the-year awards ceremonies.

Greg Burnham, has been a BEST and FIRST robotics sponsor at a local high school with a high percentage of low socio-economic standing students for ten years. He describes the impact of the robotics programs at his school and his personal motivation as follows: 
International Journal for Service Learning in Engineering Special Edition, pp. 406-423, Fall 2014

ISSN 1555-9033

"High school robotics provides a place for some kids to experience team dynamics outside of sports. They have a job or role they must fulfill for the team to accomplish its goals. At my high school the robotics team provided a positive place for students to be after school hours and in contact with role models who were in college. It engaged the students in conversations about college and their future. Very few of these conversations and role models are available to them at home or in the neighborhood. Several times a college mentor sat students down and worked through college and scholarship applications with them.

Robotics programs are in favor in education in Texas at the moment; career and technology education is the current hot button but it has not always been. I have always had administrations approval for robotics teams but there has not always been a lot of support. We have hosted robotics competitions for ten years and relatively few administrators, teachers or students have ever attended one. School district budgets vary from year to year and financial support was always given to the robotics team but amounts were often small. Parents supported their kids in robotics for the most part but often it was back burner to sports participation and family functions. When parents and administration realized college mentoring was occurring at robotics support increased somewhat.

I personally sponsor robotics teams as an extension of my teaching. It is an effective way of demonstrating real world application of science and math. It models job dynamics, teaches students teamwork and they gain confidence in themselves as the robot comes together and performs its tasks as designed and programmed, even if it does not win the competition. When they do make that connection and choose a direction in life, college or technical work, it is a lot more rewarding for me than giving them a grade on a paper.

Students have told me multiple times, that having robotics club participation on their college applications and job resumes helped them get in or get the job. In interviews they were often asked to elaborate and got favorable responses. The robotics programs have not created a seamless pipeline to college but they have provided a boost to many of our high school students and have produced some college graduates and some technical careers out of a community that has very little experience with either of those.

I have been able to track 61 students who participated in BEST or FIRST Robotics over the last 10 years and who have graduated as of September 2014. $11.5 \%$ have graduated from college or technical school (3 STEM degrees, 2 Fine Arts, 1 Marketing/Communications and 1 MA of Public Administration); $45.9 \%$ are currently enrolled in a college; $81.9 \%$ attended college for at least 1 year."

Personal statements from high school team members on their experiences in FIRST are interesting. Team 1817 membership along with the immediacy and urgency of the build season, the road trips, and the raw energy of the competition events is generally viewed as fun. Once fully engaged with the team, students lose track of the reasons they might have had to join in the first place. When asked to reflect on what they feel is important about FIRST their articulation is notable for the sense of self-efficacy expressed and the confidence they have gained in their own abilities. Team 1817 members describe the benefits of the program in the following ways:

"FIRST to me is a way to plan for my future. Before FIRST I wasn't decided what I was going to do with my life. I came to FIRST to learn, but I stayed for the fun and friends."

"In my two years as a member of Team 1817, it has greatly impacted my life. FIRST confirmed to me that I have a passion for engineering and robotics. That confirmation is what led me to my decision to major in engineering in college. FIRST has allowed me to use tools and 
machinery that I would never have used outside of FIRST robotics. [...] FIRST has greatly expanded my mechanical and electrical engineering knowledge. I now know how to wire Jaguars ${ }^{1}$ to a power distribution board and into the C-RIO ${ }^{2 \text { ". }}$

"First Robotics is the foundation for a better life for me. I have received immense amounts of knowledge since joining, from the technical things such as wiring and using tools, to the life lessons of friendship and family. Today we may be building fairly simple robots that play basketball, but tomorrow the spark of curiosity FIRST created may lead to top engineers building things that are essential for our survival. I am truly thankful to be a part of such an amazing team. FIRST has driven me to reach for higher objectives - I now want to become a biomedical engineer, something I always thought was out of my reach before I joined Team 1817."

"FIRST to me isn't just a hobby, it's a life changing experience. I've obtained many skills by participating in FIRST, I wouldn't have learned elsewhere. It truly has given me a greater appreciation for engineering and strengthened my choice to go into the engineering field. I've also gained friends that I would have never met without robotics. Team 1817 has become my family and we've grown so much as a group. I'll be excited and blessed to come back and become a mentor next year and spread my experiences with future students."

"I like FIRST because it has influenced me more than any other influence. It brought me into contact with people who I never would have come into contact with otherwise. It gave me experiences that I would have never had elsewhere. It let me talk to people and discuss new things. Lastly my experiences let me determine what I wanted to major in which led to me choosing to go to Texas Tech for my education."

The robotics programs provide continuity across university matriculation as well as across high school matriculation while connecting participants with professionals Keeping these engineering professionals engaged with the community and especially with young people actively making career choices is a key part of changing the perception of the value of engineering, and reversing the trend of diminishing engineering enrollments.

While there is a general agreement among the authors and participants that FIRST robotics is successful in creating excitement about STEM, providing valuable hands-on problem solving skills, and creating a strong network and friendships among participants, mentors, and volunteers, there are also doubts in how far it successfully prepares high school students for a successful college career in engineering which requires good foundations in math and sciences. In an informal voluntary survey at a regional FIRST Robotics competition where the robots were throwing Frisbees participants were asked to describe a mathematical model of the Frisbee's trajectory and to develop an algorithm for keeping score in the game. Very few FIRST team members were interested in participating and out of the 10 answers received over half of them only contained sarcastic comments suggesting that participants did not see the connection between the questions asked and the competition. While two students developed trajectory calculations that only contained minor mistakes, nobody got close to describe an algorithm for the scoring scheme. A stronger emphasis from mentors, coaches, and teachers to integrate math, physics, and computer science concepts into the robotics design despite the limited time available would help to overcome this issue.

\footnotetext{
${ }^{1}$ Solid state motor controllers

${ }^{2}$ National Instruments embedded real time controller
} 


\section{VAlue OF K-12 Robotics Challenges to Engineering Faculty}

Faculty at research universities are expected to perform research and publish their findings. While the first two authors of this paper basically organize the K-12 robotics challenges because they believe it is the right thing to do, they also managed to take their activities beyond being simply a "service" component on their professional resumes. While organizing the competition is within their comfort zone, assessing the impact of the programs on the participants' interest in STEM fields was outside of the expertise of these engineering faculty. Thus, collaborations with colleagues from sociology, social work, and education were built to accomplish this task. An ongoing collaboration resulted in the creation of a survey assessing engineering skills gained by first year engineering students through the LEGO robotics service learning component.

The authors were successful in publishing their results in journals such as IEEE Transaction on Education $^{24}$, American Journal of Engineering Education ${ }^{25}$, and the IEEE/ASEE Frontier in

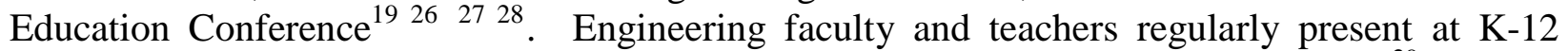
STEM conferences for K-12 teachers and also hold robotics workshops at these events ${ }^{29}$. One of them was awarded the TTU Integrated Scholar Award ${ }^{30}$ for the integration of teaching, research, and service around robotics as well as the Hewlett-Packard/Harriett B. Rigas Award from the IEEE Education Society. The other one received the TTU President's Excellence in Teaching Award. Existing university-wide programs such as the Service Learning Fellow and Mentor Program have been extremely helpful to meet faculty from outside of engineering with similar interests and to build cross-college networks for collaborations.

However, the TTU faculty authors still feel that the work they are doing is not rewarded by the university in the same way as "traditional" research is. At this point, they would not recommend junior tenure track faculty to get involved, despite the existing network. Assigning service learning students to schools, organizing events and trips, and building a network of collaborators take up a large amount of time not available to publishing papers and writing proposals for external funding. Also, no succession plan exists in case one of them retires.

\section{Best Practices}

While every location, school district, history, socio-economic environment is different, there are some experiences we made that we think have universal applicability and which are listed below.

Implementation and Growth of Robotics Programs: When we started offering GEAR and FIRST Robotics programs, we already had long-standing experiences with BEST robotics and a list of potential contacts. We started small and exploited the existing contacts. We did try a topdown approach by sending out information about the programs to superintendents, and school administrators but had limited success with recruiting participants that way. At the time, robotics was not a hot topic, so this strategy might work a little better these days, where nearly every school district is trying to implement a robotics program. We mostly recruited participants through existing informal networks, e.g. colleagues with children in the right age range. The programs saw significant growth through parents' involvement. Many middle schools started GEAR robotics when elementary school participants moved on to middle school and their parents made the effort of convincing the principal and a sponsoring parent of the value of participating in the program. We regularly do send out information about our programs through mailing lists. During recent years, GEAR has seen an increase in participating schools that 
already have a robotics program in place and were looking for a challenge for their robots to complete.

Avoiding an up-front investment at the participants' side by providing LEGO kits for check out or having grants available to acquire the robot base kit for FIRST together with offering some professional development for teachers new to robotics were additional powerful recruiting tools. Our original "New Teacher Training Workshop" for GEAR was a three hour Saturday morning event but it provided sufficient hands-on opportunities for teachers to where they left the event full of confidence and with a network of contact of other teachers in a similar position. For the last few years, a FIRST robotics kickoff event open to all local teams was held at TTU and accompanied by a robot build workshop during which teams build a operable moving robot base from their kit that they then improve during the build season at their respective schools.

Flexibility and Adaptability: Programs that offer flexibility in their implementation to adapt to local constraints have seen the greatest growth over the years. With the GEAR program, we have been able to set its duration during the spring semester, which created the opportunity to send engineering mentors to local participating teams for class credit and guaranteed the availability of student volunteers for the on-campus events. We also we able to discuss upcoming GEAR game themes with the GEAR organizers based upon funding opportunities. We offer the same flexibility to teachers who decide how the robotics program is implemented into their school day and who gets to participate. The ability to shape the program has created buy-in at all levels. The drawbacks of small grass-root programs are that they do not have a national reputation and it takes more effort to explain the goals and modalities of the program to participants and sponsors and to advertise events.

Collaboration: Collaboration has probably been the most important ingredient to success. Collaboration between local robotics program organizers created a conflict-free schedule of events, shared use of equipment required for competition events, an extended base of volunteers and school contacts, and the opportunity to exchange experiences. It also offered opportunities for high school participants to get involved in elementary and middle school robotics programs either as mentors or as volunteers, e.g. the FIRST robotics participants manufacture custommade trophies for the GEAR competition while expanding their skills in computer aided design and manufacturing.

Collaboration with school teachers is essential to avoid conflicts with other important school events such as state required testing or other competitions/events that robotics participants will attend and to learn about school district constraints. They create awareness of the robotics programs in their school communities and among administrators and are instrumental in securing funds to travel to robotics events or pay for participation fees.

Collaboration with university centers and programs has facilitated the quality and growth of our robotics programs. We have collaborated with the TTU T-STEM Center regarding the development of teacher professional development courses for robotics, provided them with LEGO robotics kits to be used during these summer/weekend courses, while they have advertised our programs to their participants and through their mailing lists. The TTU Service Learning program has been instrumental in implementing the robotics mentoring as a for credit service learning program and experiences made were shared with faculty new to service learning. The Office of Diversity and Community Engagement has financially supported the robotics programs while we have provided with program and participation data that is included in the 
annual university community engagement report and used for the reapplication for the Carnegie classification as "Community Engaged" institution. We have also provided robotics content and instructors for summer and weekend camps organized out of this office.

Multidisciplinary collaboration among university faculty has resulted in the creation of instruments used to evaluate the impact of the robotics programs. Combining the expertise of faculty from education, sociology, and engineering also created new opportunities for dissemination of the results in discipline specific journals.

Engineering Student Involvement: Engineering student mentors provide an engineering perspective to K-12 robotics team members and teachers while offering a near-peer nonthreatening learning environment that is beneficial to all participants. Secondary school teachers are generally relieved to have additional technical expertise while university undergraduates are happy to have adult authority figures to maintain order. High school students see university participation as an achievable goal with their undergraduate mentors as believable role models. Undergraduates experience enhanced feelings of self-efficacy and engagement when their guidance and expertise are valued. Several models have been used to engage engineering students in robotics: through course credit for a service learning project, in collaboration with student organizations looking for opportunities for meaningful community service related to their engineering careers, and as hourly paid university employees. Providing financial support to students increases their commitment to the project while helping them to cover their financial needs through activities meaningful to their career.

Communication and Advertisement: Communication and advertising are crucial to creating awareness of the robotics programs and to meeting all participants' professional goals. Robotics teachers and university faculty need to convince changing administrators of the value of their robotics programs. Frequent announcements, invitations to fundraisers and celebrations of small victories were successful strategies. Ensuring that administrators, parents and community partners knew when a grant (no matter how small) was received, a new mentor or sponsor was recruited or a contribution was submitted to a journal or conference workshop were other important aspects. Basically, keeping administrators in the loop reminded them that the robotics team is just like a sports team and made them a partner in the team.

Community exposure is vital and public events such as art walks, homecoming parades, sports assemblies and any other public event where you can drive a robot boosts community awareness. Arranging for the public to safely operate the robot increased interest even more. Finally, sponsors expect to get media exposure through their financial investment.

Presenting the robotics programs through various media also provides opportunities for new collaborations and recruitment of new participants. We have been contacted several times by teachers, parents, afterschool clubs, and university faculty who were interested in participating in our program, for example 4-H clubs have been participating in all our robotics programs during the last two years.

Funding and Program Evaluation: Continued funding is an important factor in the organization of robotics events and the participation in it. The amount of required funding largely depends on the robotics program and the local cost for staff and venues. Quality community engagement cannot be made contingent on the availability of grant funding. By the time our initial Texas Workforce Development grant ended teachers and K-12 participants had 
put our robotics challenge on their annual calendar of events. There is much talk of accountability in outreach programs. How effective are the programs? What is the return on investment? What are the five-year graduation rates? How can we improve the program? To help answer these questions it is important to establish infrastructure for collecting participation data and establishing performance metrics. This infrastructure should be created early and is best performed by multidisciplinary teams of researchers.

\section{CONCLUSIONS}

Two important elements, GEAR and FIRST Robotics, of a pipeline of robotics programs have been described together with the interconnections between and impacts on all participants who are key to the achievements of this pipeline. A distinctive and major strength of the robotics programs offered by WCOE is the involvement and collaboration between different groups, including K-12 students, their teachers, engineering students, faculty, the TTU T-STEM Center, and industry partners. Another strength is the use of shared resources, which allows offering all programs continuously over multiple years on a tight budget.

While some quantitative assessment was performed over the years, the majority of the results presented here stem from personal experiences. Tracking students from elementary school to college is a challenging and costly task and not everyone who is interested in a continued participation in robotics also gets the chance to do so due to school and family constraints. However, during the last couple of years, we have seen several students participating in the capstone robotics program, FIRST Robotics, who started in elementary school and made it through the whole robotics pipeline. Without the collaboration of faculty and teachers involved in the different programs, this knowledge would not exist.

After 20 years of effort, our GEAR, BEST, and FIRST robotics programs now offer STEM education and enrichment to about 2000 students annually, many of them from rural areas and/or Title 1 schools. While it was a significant effort to recruit schools into these programs when they started, the organizers are now approached by new schools interested in participation who heard of these programs by word of mouth. Teachers and parents have taken an active role in getting these programs into their schools. While we have drawn a mostly positive picture in describing the value of the robotics pipeline to all participants, we have also elaborated on our experiences and existing challenges.

\section{ACKNOWLEDGEMENTS}

The authors would like to thank Halliburton Education Foundation, Xfab, Boeing, IEEE South Plains Section and Texas Tech University for their generous support of the robotics programs. 


\section{REFERENCES}

${ }^{1}$ Hobson R. S, "The changing face of classroom instructional methods: Service learning and design in a robotics course", 30th ASEE/IEEE Frontiers in Education Conference, Kansas City, MO, 2000

${ }^{2}$ Mitchell R, Warwick K, Browne W. N, Gasson M. N, Wyatt J, "Engaging Robots: Innovative Outreach for Attracting Cybernetics Students", IEEE Trans. on Education, Vol. 53, No. 1, 2010.

${ }^{3}$ Habash R.W.Y, Suurtamm C, "Engaging High School and Engineering Students: A Multifaceted Outreach Program Based on a Mechatronics Platform”, IEEE transactions on education, Vol. 53, No. 1, 2010.

${ }^{4}$ Grimes J, Seng J, "Robotics Competition: Providing Structure, Flexibility, and an Extensive Learning Experience", 38th ASEE/IEEE Frontiers in Education Conference, Saratoga Springs, NY, 2008.

${ }^{5}$ Whitacre College of Engineering, Texas Tech University, [Online]. http://www.coe.ttu.edu/, accessed September 2014.

6 Texas Tech University T-STEM Center, [Online]. http://www.depts.ttu.edu/tstem/, accessed September 2014.

${ }^{7}$ Institute for the Development and Enrichment of Advanced Learners, Texas Tech University, [Online]. http://www.ideal.ttu.edu/, accessed September 2014.

${ }^{8}$ Texas Tech University Teaching, Learning, and Professional Development Center, Service Learning Program Website, [Online]. http://www.tlpd.ttu.edu/servicelearning/about.asp, accessed September 2014.

${ }_{9}^{9}$ Get Excited About Robotics, [Online]. http://www.gearrobotics.org, September 2012.

${ }^{10}$ Get Excited About Robotics, Texas Tech University [Online]. http://www.coe.ttu.edu/stem/gear/, accessed September 2014.

${ }^{11}$ Boosting Engineering, Science, and Technology, [Online]. http://www.bestinc.org/, accessed September 2014.

${ }^{12}$ FIRST Tech Challenge, [Online]. http://www.usfirst.org/roboticsprograms/ftc, accessed September 2014.

${ }^{13}$ FIRST Tech Challenge - Texas Tech - Lubbock, [Online]. http://www.depts.ttu.edu/coe/stem/ftc/, accessed September 2014.

${ }^{14}$ FIRST Robotics, [Online]. http://www.usfirst.org/roboticsprograms/frc, accessed September 2014

${ }^{15}$ FIRST Team 1817 - Llano Estacado RoboRaiders, [Online]. http://www.team1817.org/, accessed May 2012.

${ }^{16}$ FIRST LEGO League, [Online]. http://www.firstlegoleague.org/, assessed September 2014.

17 EV3 Robotics Online Course, [Online]. http://www.coe.ttu.edu/stem/gear/EV3/, accessed December 2014.

${ }^{18}$ FIRST in Texas, [Online]. http://www.firstintexas.org/, accessed December 2014.

${ }^{19}$ T. Karp. Teaching a Service Learning Introductory Engineering Course - Lessons Learned and Improvements Made. IEEE/ASEE Frontiers in Education Conference, pp. F1E 1-5, Rapid City, SD, USA, October 2011.

20 TTU Undergraduate / Graduate Catalog 2013/2014, [Online]. http://www.depts.ttu.edu/officialpublications/courses/ENGR.php, September 2014.

${ }_{21}$ Texas Tech University, Public Access to Course Information, [Online]. http://www.ttu.edu/courseinfo/, accessed September 2014.

${ }^{22}$ CAN Bus, International Standard ISO11898, 2003.

${ }^{23}$ Justin Griggs; Master's Thesis, Electrical and Computer Engineering, Texas Tech University; Texas Digital Library; http://repositories.tdl.org/ttu-ir/handle/2346/46694

${ }^{24}$ Karp, T., Gale, R., Lowe, L., Medina, V. and Beutlich, E., "Generation NXT: Building Young Engineers with LEGO's", IEEE Transactions on Education, Special Issue on Outreach to Prospective Electrical, Electronic, and Computer Engineering Students, vol. 53, issue 1, pp. 80-87, February 2010. 
${ }^{25}$ T. Karp and P. Maloney. Exciting Young Students in Grades K-8 About STEM Through an Afterschool Robotics Challenge. American Journal of Engineering Education, Spring 2013 Special Edition, vol. 4, issue 1, pp. 39-54.

${ }^{26}$ T. Karp and A. Schneider. Evaluation of a K-8 LEGO Robotics Program. IEEE/ASEE Frontiers in Education Conference, pp. T1D 1-6, Rapid City, SD, USA, October 2011.

${ }^{27}$ T. Karp and R. Gale. Sustainability of K-12 Engineering Outreach Activities beyond the Grant Period. IEEE/ASEE Frontiers in Education Conference, 5 pages, San Antonio, TX, USA 2009.

${ }^{28}$ E. Levy, M. Tan, R. Gale, T. Karp, and A. Barhorst. Affordable K-12 Robotics Programs. IEEE/ASEE Frontiers in Education Conference, pp. T1D 1-6, Rapid City, SD, USA, October 2011.

${ }^{29}$ Patricia Maloney, Lauren Dent, Tanja Karp A New Method of Assessing the Effects of a ServiceLearning Class on Engineering Undergraduate Students, International Journal for Service Learning in Engineering, Humanitarian Engineering and Social Entrepreneurship, pp. 29-47, Fall 2013.

${ }^{30}$ Integrated Scholar Tanja Karp, [Online]. http://today.ttu.edu/2014/06/2014-integrated-scholaraward-tanja-harp/ 